\title{
Psychometric Properties of the Maslach Burnout Inventory Adaptation and Validation among Moroccan Mathematics Teachers
}

\author{
https://doi.org/10.3991/ijoe.v18i03.28029 \\ Ikram Douelfiqar $^{1(\mathbb{})}$, Youssef El Madhi², Hanan El Faylali ${ }^{1}$ \\ 'Ibn Tofail University, Kenitra, Morocco \\ ${ }^{2}$ Regional Center for Education and Training Trades, Rabat, Morocco \\ ikram.douelfiqar@uit.ac.ma
}

\begin{abstract}
- the teaching profession is particularly vulnerable to the development of stress and burnout syndrome, this research is used to adapt the Maslach Burnout Inventory (MBI) to members of middle and high schools in Morocco. This study aims to evaluate the psychometric properties of Maslach Burnout Inventory (MBI) in terms of validity, reliability, and sensitivity. The sample consists of 218 mathematics teachers, working in public schools in Marrakech-Safi region (Morocco). The psychometric properties were examined by the following analyses: confirmative factor analysis (CFA) to test the validity of the Statistical model, Reliability (Cronbach's alpha), exploratory factor analysis (EFA) to extract factors and complete dimensionality Cronbach's $\alpha$ reliability analysis gives a value of (0.814), Principal component analysis with varimax Rotation gives three factors and explains $54.22 \%$ of the total variance. The three dimensions give values well above the accepted minimum reliability threshold namely (0.847) for emotional exhaustion (0.766) for depersonalization and $(0.720)$ for a sense of personal accomplishment. The overall adjustment of the model and very satisfactory, Which affects the $(0.71)$. The results indicate that the main psychometric properties of reliability and validity of the theoretical model of MBI appear to be satisfactory for the study of burnout syndrome in the cultural context of Moroccan teachers.
\end{abstract}

Keywords-MBI, psychometric properties, validation, Moroccan, mathematics, teachers

\section{Introduction}

The burnout syndrome is a set of reactions resulting from situations of chronic professional stress in which the commitment dimension is predominant. It manifests itself in three forms: emotional exhaustion, depersonalization and a decrease in personal accomplishment at work[1]. 
Different instruments for measuring burnout has developed for to account for this syndrome and to make comparisons between studies. The most widely used instrument is still today the Maslach Burnout Inventory (MBI). It measures the three dimensions of this syndrome previously defined by Maslach.

The MBI questionnaire has been adapted to apply not only to human service professions but also to all types of professions in general. An updated definition of burnout, constructed from the latest version of the MBI, is that proposed by Maslach[2].

However, several studies of the MBI in terms of psychometric properties in different cultures and industries have yielded varied results, and cross-cultural comparisons of burnout diagnosis among teachers are completely different[3], a brief look at the working conditions of Moroccan teachers reflects the fact that their profession has a significant painful dimension.

Faced with very heavy demands and the non-recognition of the hardship of their profession, Moroccan teachers report a proven psychological fragility developing various pathologies at work[4].

The Moroccan government has initiated numerous educational reforms. These reforms have made it possible to achieve certain notable advances such as the improvement of infrastructure, pedagogical and didactic equipment and the social conditions of teachers[5].

However, the workload and emotional burden of teachers continues to increase. Similarly, the physical working conditions these work demands can jeopardize the health of Moroccan teachers[6],[7].

Indeed, to protect the psychological health[8] of these resources, it is necessary to produce a diagnostic tool for burnout valid for the cultural context of teachers.

The purpose of this study was the translation and psychometric validation of the MBI for the Moroccan population, in order to, becomes a useful tool in the assessment of burnout in Moroccan teachers.

\section{$2 \quad$ Material and method}

\subsection{Measures}

The Maslach Burnout Inventory MBI Questionnaire is a measure of burnout, composed of 22 questions that defined by three subscales[9]:

- Emotional Exhaustion (EE) composed of 9 items $(1,2,3,6,8,13,14,16,20)$ and (result between 0 and 54).

- Depersonalization (DP) composed of 5 items $(5,10,11,15,22)$ and (result between 0 and 30).

- Personal Accomplishment (EE) composed of 8 items (4, 7, 9, 12, 17, 18, 19, 21) and (result between 0 and 48).

Each with 7-point, Likert-type, frequency response scale $(0=$ never, $1=\mathrm{a}$ few times a year or less, $2=$ once a month or less, $3=$ a few times a month, $4=$ once a week, $5=\mathrm{a}$ few times a week, $6=$ every day)[10]. 


\subsection{Translation procedure}

The translation of the MBI was carried out by two bilingual people working in the field of education, an associate professor of the French language working in the Regional Center for Education and Training (CRMEF) in Safi (Morocco) and a language teacher works in a public high school. The questionnaires distributed online via Google Forms and the socio-demographic data recorded, this process followed by a pre-test of the instrument with 76 teachers to verify our questionnaire and validate our measurement scale.

\subsection{Participants}

The validation of the instrument was carried out with a sample of 218 mathematics teachers working in the public sector from 16 high schools and 30 public middle schools. Of the city of SAFI (Marrakech-Safi, Region, Morocco). I found that $39 \%$ of women and $61 \%$ of men, the average age is $38 \pm 22$ of which $61 \%$ are married, and $37 \%$ are single, $58 \%$ of the them have a bachelor's degree, and $22 \%$ have a Master's degree, and $2 \%$ have a $\mathrm{PhD}$ degree with years of seniority that varies between 3 and 15 years.

\section{$2.4 \quad$ Statistical analyses}

Statistical analyses were performed using SPSS V25 Software (IBM Corporation, Armonk, NY) and SmartPLS v3 Pro software[11]. The feasibility of the instrument was tested through the Principal Component analysis (PCA), which allows us to clean our measurement scale to achieve acceptable reliability compared to the cronbach's $\alpha$ indicator, the reliability was examined by calculating the same coefficient for the three dimensions. The data were subjected to an Exploratory Factor Analysis (EFA) to extract the factors and test the dimensionality of the questionnaire. The KMO test that was designed by Kaiser, Meyer and Olkin was calculated to assess the suitability of the sampling. It is significant when it far exceeds the threshold minimum, the Bartlett's test of Sphericity is statistically significant if the risk threshold is close to zero $(p<0.05)$.

To model the structures of the links between the data, we used the structural equation model (SEM). The coefficient of determination $\left(\mathrm{R}^{2}\right)$ allows estimating the share of variation of our instrument explained by the three explanatory dimensions[12]. The predictive relevance $\left(\mathrm{Q}^{2}\right)$ of the structural model gives satisfactory results if it exceeds the minimum accepted threshold. The quality of adjustment is calculated by the Goodness of Fit index (GoF) which makes it possible to judge to what extent the theoretical structural model corresponds to the empirical data.

\section{Results}

\subsection{Internal consistency of theoretical dimensions and deletion of items}

In our study, we measured the burnout using the Maslach Burnout Inventory (MBI) instrument with 22 items that follow a 5-point measurement scale (1: not at all agree, 5: 
all agree). Cronbach's $\alpha$ reliability analysis gives a value of 0.626 these results forces us to delete six items $6,7,9,14,21,22$ that are inconsistent with other items in order to increase the alpha value to 0.814 (See Table 1).

Table 1. Analysis of the validity of the measurement scale of variables (Before and after deletion of unreliable items)

\begin{tabular}{|l|c|c|c|c|}
\hline \multirow{2}{*}{ Variable } & \multicolumn{2}{|c|}{ Reliability of Scales Before Deleting Items } & \multicolumn{2}{c|}{ Reliability of Scales After Deleting of Items } \\
\cline { 2 - 5 } & Number of Items & Cronbach's $\boldsymbol{\alpha}$ & Nbr Items KMO & Cronbach's $\boldsymbol{\alpha}$ \\
\hline MBI & 22 & 0.62 & 16 & 0.814 \\
\hline
\end{tabular}

The results show that the Alpha indicator has been significantly improved after item deletions that reduce alpha reliability. Therefore, we can say that the items manage to effectively measure our model.

\subsection{Exploratory factor analysis (EFA)}

Principal component analysis with varimax rotation gives three factors whose eigenvalues are greater than one and explain $54.22 \%$ of the total variance. The three dimensions are well defined. The first factor, which includes four elements constituting the Depersonalization dimension, explains $34.14 \%$ of the total variance. The second factor has seven elements constituting the Emotional Exhaustion dimension, with 12.94 of the total variance; the third has five items constituting the Personal Accomplishment dimension, which explains $7.175 \%$ of the total variance (See Table 2).

The principal component analysis identified 3 dimensions that make up the Maslach Burnout Inventory specific to Moroccan Teachers, The EE dimension ( 7 items), the DP dimension (with 4 items), and the PA dimension (5 items). Each of these items shows a great correlation with its own dimension. The analysis of the items gives significant results as to the validity and reliability of the scales; we were able to obtain a significant KMO index of 0.889 a value that far exceeds the only accepted minimum. In addition, the Bartlett's test of Sphericity gives a statistically significant value to the risk threshold of 5\%[13], for all items in Maslach Burnout Inventory with significance of 0.000 , which is below the threshold of 0.05 . For the Cronbach's $\alpha$ values, we noticed that the measuring items of the dimensions of MBI namely: (EE, DP, and PA) give values well above the accepted minimum reliability threshold, i.e. 0.847 for the dimension EE 0.766 for the DP and 0.720 for the PA.

The total variance explained shows the share of each dimension in the MBI theoretical model formation, we have the EE dimension which gives a variance of $36.73 \%$ followed by the DP dimension with $11.90 \%$ at the end the PA dimension with $7.10 \%$. 
Table 2. Factor analysis and cronbach's $\alpha$

\begin{tabular}{|l|c|c|c|}
\hline \multicolumn{1}{|c|}{ Items } & EE & DP & PA \\
\hline EPPEO2 & 0.754 & & \\
\hline EPPEO1 & 0.720 & & \\
\hline EPPEO9 & 0.644 & & \\
\hline EPPEO3 & 0.643 & & \\
\hline EPPEO5 & 0.638 & & \\
\hline EPPEO6 & 0.585 & & \\
\hline EPPEO8 & 0.506 & & \\
\hline DPERS5 & & 0.704 & \\
\hline DPERS3 & & 0.702 & \\
\hline DPERS4 & & 0.687 & \\
\hline DPERS1 & & 0.605 & \\
\hline ACPERS1 & & & 0.725 \\
\hline ACPERS5 & & & 0.722 \\
\hline ACPERS4 & & & 0.703 \\
\hline ACPERS6 & & & 0.540 \\
\hline ACPERS3 & & & 0.493 \\
\hline Cronbach's $\alpha$ & & 1297.229 & \\
\hline \% of the explained variance & 36.734 & 11.901 & 7.103 \\
\hline \% of total variance explained & & 55.737 & \\
\hline Precision measurement of Kaiser-Meyer-Olkin sampling (KMO) & & 0.889 & \\
\hline Bartlett sphericity test: & & \\
\hline Chi-square approximate & & & \\
\hline $\begin{array}{l}\text { D1 } \\
\text { Significance of Bartlett }\end{array}$ & & \\
\hline
\end{tabular}

\subsection{Analysis of the structure of the dimensions the Maslach Burnout Inventory}

In order to identify the existing relationships between the dimensions of Maslach Burnout Inventory we calculated the score for each dimension, The results show that the two dimensions Depersonalization (DP) and emotional exhaustion (EE) are positively correlated with each other with a value of 0.625 , on the other hand, we have a negative relationship between the Personal Accomplishment dimension (PA) and the (EE) and the (DP).This means that these two dimensions vary in opposite directions, but with relatively average correlation coefficients, $(-0.423$ and -0.491$)$. The analysis of variance by sex and age for all three dimensions shows that the relationship is only significant for the relationship between gender and (DP). (See Table 3) 
Table 3. Factor Descriptive and correlation analyses between the dimensions of the Maslach Burnout Inventory specific to Moroccan Teachers and between these dimensions and age and gender variables

\begin{tabular}{|l|c|c|c|c|c|}
\hline \multicolumn{1}{|c|}{ Variables } & Means & Standard Deviation & EE & DP & AP \\
\hline EE & 4.180 & 1.391 & & & \\
\hline DP & 2.591 & 1.391 & 0.625 & & \\
\hline PA & 2.010 & 0.881 & -0.423 & -0.491 & \\
\hline Age & 38.09 & 22.501 & 0.128 & 0.061 & 0.015 \\
\hline Gender & - & - & 0.034 & $0.201 *$ & 0.113 \\
\hline
\end{tabular}

Note: * the correlation is significant at level 0.05 .

\subsection{Structural equation model analysis (SEM)}

To test our model we chose the PLS structural equation method. Structural equation models (SEM) are multivariate models used to model the patterns related to data. The interest of structural equation modelling lies essentially in its ability to simultaneously test the existence of causal relationships between several latent variables[14].

Aiming at evaluating a reflective structural model we must calculate a set of indicators that allow the measurement of $[15]$ :

- Coefficient of determination $\left(\mathbf{R}^{2}\right)$

- Predictive relevance $\operatorname{Model}\left(\mathbf{Q}^{2}\right)$

- Goodness of Fit(GoF)

The coefficient of determination $\left(\mathrm{R}^{2}\right)$, allows estimating the share of variation of Maslach Burnout Inventory explained by the three explanatory dimensions for our structural model, the MBI model is composed by three dimensions (EE, DP and, PA) As shown in (see Table 4), the explanatory power of these three dimensions is estimated at 0.993 this means that the three dimensions: (EE, DP and, PA) bet to effectively measure instrument variation (MBI) and are important factors in the formation of MBI.

Table 4. The results of the structural equation model analysis

\begin{tabular}{|l|c|c|}
\hline \multicolumn{1}{|c|}{ Indices } & Model & Thresholds of Acceptability \\
\hline $\mathrm{R}^{2}$ & 0.993 & $\mathrm{R}^{2} \geq 0.19$ \\
\hline $\mathrm{Q}^{2}$ & 0.260 & $\mathrm{Q}^{2}>0$ \\
\hline GoF & 0.71 & $\mathrm{GOF} \geq 0.1$ \\
\hline
\end{tabular}

The predictive relevance $\left(\mathrm{Q}^{2}\right)$ of the structural model gives satisfactory results that exceed the accepted minimum threshold, which shows that we have a good predictive relevance of our MBI model. In addition, the overall adjustment of the model is very satisfactory it touches the 0.71 , a value that reflects a very good quality of adjustment. The latter allows us to formulate the validation of the three-dimensionality of the three-dimensional character of the Maslach Burnout Inventory translated into Arabic 
specific to Moroccan math teachers. The Moroccan version of 16 items of MBI Specific to teachers proposed by our research is therefore a validated structure (See Figure 1).

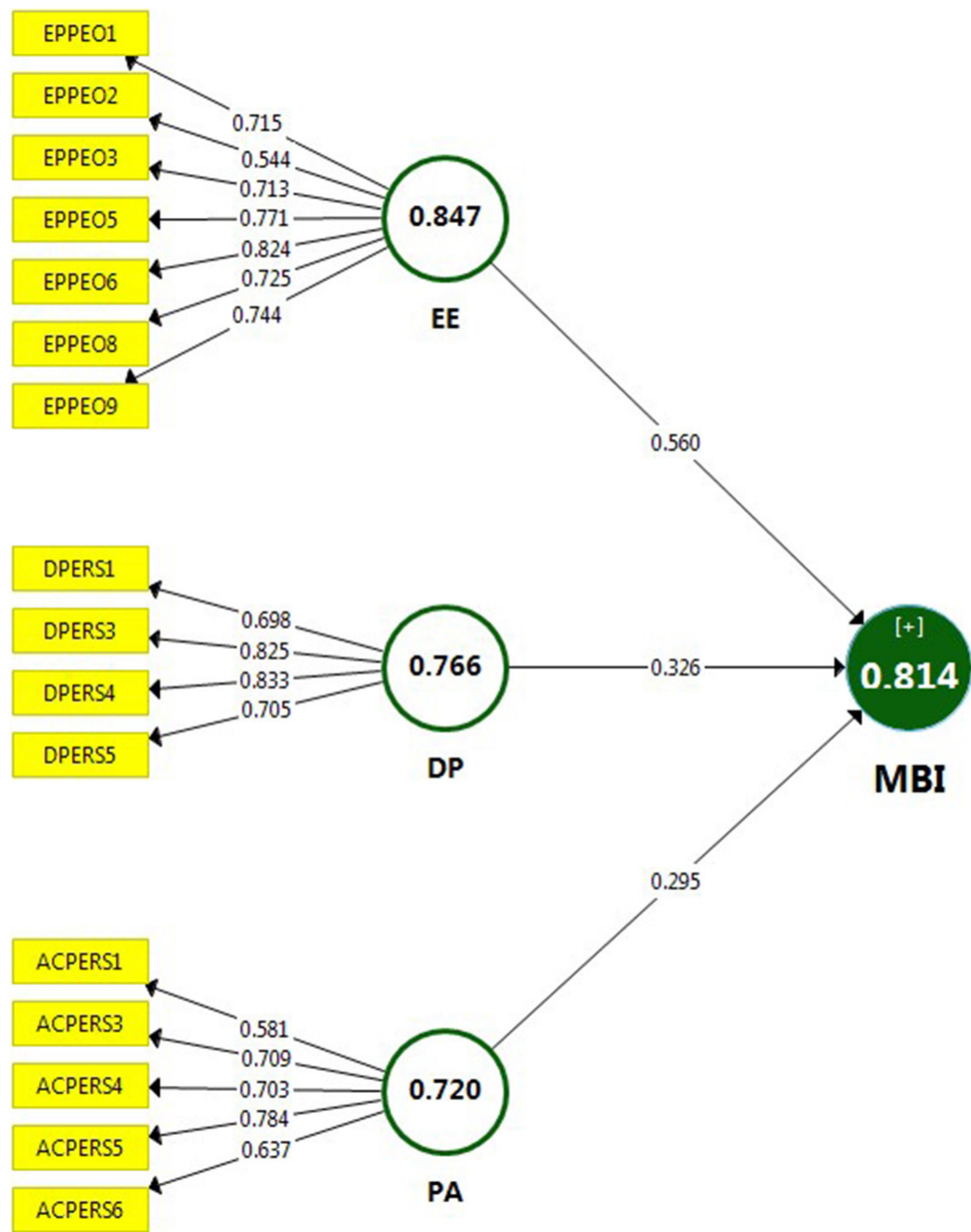

Fig. 1. The results of the MBI measurement model Source: Structural equation modeling software "SmartPLS". 


\section{Discussion}

The main objective of this study was to construct and test the factor structure, internal reliability, sensitivity, and validity of a measuring scale translated into Arabic of the burnout of Moroccan teachers, designed according to the three-dimensional theoretical model of Maslach Burnout Inventory. The tool composed of 16 items, was validated on a representative sample of mathematics teachers at middle and high schools in the city of SAFI located in western Morocco in the region of Marrakech-Safi. Using sequential analysis (EFA and CFA). Several validation tests have shown the inconsistency of some theoretical items from the MBI instrument of 22 items with the characteristics of samples studied.

Our results, however, contradict the results of previous studies of samples of non-Western teachers (e.g. Abu hilal \& al (2018))[16] that have confirmed that burnout is a multidimensional concept, (the existence of four dimensions). Similarly, the factor structure of burnout in this survey is remarkably consistent with other studies (such as Won sunchen \& al (2014) and Abdeslam Amri (2019))[17],[18]. For our study, we excluded items $(6,7,9,14,21,22)$ and then kept a model of 16 items.

This inconsistency of these items could be explained by the characteristics of the teaching profession, and also the nature of the mathematics subject taught which constitutes, great learning difficulty and it is very often related to high stress[19].

The exploratory factor analysis retained the three dimensions of the 16 items of the MBI specific to Moroccan mathematics teachers with very positive results. For our study, Cronbach's $\alpha$ on the global scale $(0.814)$ proves good reliability of items with a value that far exceeds 0.7 as well as those of emotional exhaustion (0.847) depersonalization (0.766) and the feeling of personal accomplishment (0.720) are satisfactory.

We propose to use this measuring instrument for research in the non-Western Moroccan Educational system for the evaluation of burnout.

\section{Conclusion}

To sum up, our study confirmed that the Moroccan version of the 16-item MBI has acceptable psychometric properties, with a well-defined internal structure and very good quality of adjustment. It was valid and appropriate to be used to facilitate future related to burnout studies for Moroccan teachers.

\section{References}

[1] R. T. Lee and B. E. Ashforth, "On the Meaning of Maslach's Three Dimensions of Burnout," J Appl Psychol, vol. 75, no. 6, pp. 743-747, Dec. 1990. https://doi. org/10.1037/0021-9010.75.6.743

[2] C. Maslach, W. B. Schaufeli, and M. P. Leiter, "Job Burnout," Annual Review of Psychology, vol. 52, no. 1, pp. 397-422, 2001. https://doi.org/10.1146/annurev.psych.52.1.397 
[3] K. J. S. Brady et al., "Describing the Emotional Exhaustion, Depersonalization, and Low Personal Accomplishment Symptoms Associated With Maslach Burnout Inventory Subscale Scores in US Physicians: an Item Response Theory Analysis," J Patient Rep Outcomes, vol. 4, no. 1, p. 42, Dec. 2020. https://doi.org/10.1186/s41687-020-00204-X

[4] S. Azouaghe, "Santé Psychologique Au Travail Dans Le Milieu Scolaire Public: Étude Des Déterminants Organisationnels Et Psychologiques Chez Les Enseignants Marocains," p. 437.

[5] V. Llorent-Bedmar, "Educational Reforms in Morocco: Evolution and Current Status," International Education Studies, vol. 7, no. 12, pp. 95-105, Nov. 2014. https://doi.org/10.5539/ ies.v 7 n $12 \mathrm{p} 95$

[6] L. Wahl, "Teacher Stress on a Sample of Moroccan Educators," p. 95.

[7] M. A. Lafraxo, M. Ouadoud, Y. El Madhi, and A. Soulaymani, "Burnout Syndrome Among Nursing Staff: Performing Data Analysis using the SPSS Statistic,” Int. J. Onl. Eng., vol. 17, no. 04, p. 145, Apr. 2021. https://doi.org/10.3991/ijoe.v17i04.20979

[8] A. Alaradi, S. Irum, N. Ebrahim, F. M. J. Mohamed, F. M. J. Hazeem, and M. Ashfaq, "The Mental Health Impact of COVID-19 Pandemic on Health Care Workers and Coping Strategies: a Systematic Literature Review,” Int. J. Onl. Eng., vol. 17, no. 09, p. 48, Sep. 2021. https://doi.org/10.3991/ijoe.v17i09.24791

[9] L. Poghosyan, L. H. Aiken, and D. M. Sloane, "Factor Structure of the Maslach Burnout Inventory: an Analysis of Data From Large Scale Cross-sectional Surveys of Nurses From Eight Countries," Int J Nurs Stud, vol. 46, no. 7, pp. 894-902, Jul. 2009. https://doi. org/10.1016/j.ijnurstu.2009.03.004

[10] C. Maslach, S. E. Jackson, and M. P. Leiter, "Maslach Burnout Inventory: Third edition," in Evaluating stress: a book of resources, Lanham, MD, US: Scarecrow Education, 1997, pp. 191-218.

[11] K. K.-K. Wong, "Partial Least Squares Structural Equation Modeling (PLS-SEM) Techniques Using SmartPLS," p. 33, 2013.

[12] C. P. Dhakal, "Interpreting the Basic Outputs (SPSS) of Multiple Linear Regression," vol. 8, no. 6, p. $5,2018$.

[13] T. J. Cleophas and A. H. Zwinderman, Statistical Analysis of Clinical Data on a Pocket Calculator, Part 2. Dordrecht: Springer Netherlands, 2012. https://doi. org/10.1007/978-94-007-4704-3

[14] A. Can and U. Asan, "A Study on the Adoption of Smart Home Devices: PLS Structural Equation Modeling," in Industrial Engineering in the Digital Disruption Era, Cham, 2020, pp. 229-242. https://doi.org/10.1007/978-3-030-42416-9_21

[15] M. de los Á. Villalobos-Alonzo and A. E. Romo-González, "Predictive Relationship of Knowledge Management and Business Innovation: a Model Based on PLS Structural Equations," JMQM, pp. 1-8, Dec. 2019. https://doi.org/10.35429/JMQM.2019.5.3.1.8

[16] M. Abu-Hilal, S. Al dafri, and H. Kilani, "Structure of Burnout among Omani Male and Female Teachers: invariance of Structure across Gender," J. educ. psychol. stud., vol. 12, no. 4, p. 739, Oct. 2018. https://doi.org/10.24200/jeps.vol12iss4pp739-749

[17] W. S. Chen et al., "Translation, Cross-cultural Adaptation and Validation of the Malay Version of the Maslach Burnout Inventory (MBI) in Malaysia," International Journal of Social Science Studies, vol. 2, no. 2, pp. 66-74, Feb. 2014. https://doi.org/10.11114/ijsss.v2i2.309

[18] "Psychometric Validation of the Maslach Burnout Inventory (MBI) Adapted to Moroccan Teachers," MLU, Jan. 2021. https://doi.org/10.37506/mlu.v21i1.2267

[19] M. A. Lafraxo, M. Ouadoud, Y. El Madhi, and A. Soulaymani, "Perceived Stress and Coping Strategies among Healthcare Professionals: a Cross-Sectional Observational Study," Int. J. Onl. Eng., vol. 17, no. 09, p. 82, Sep. 2021. https://doi.org/10.3991/ijoe.v17i09.23653 


\section{$7 \quad$ Authors}

Ikram Douelfiqar is a mathematics teacher from Morocco. She is a $\mathrm{Ph} . \mathrm{D}$ student at the Department of Laboratory of Informatics Systems and Optimization at Ibn Tofail University. She had her master's degree in teaching professions, and Bachelor's Degree in Mathematics and Informatics. Her Research interest includes E-learning, Epidemiology, and Public Health, Stress, Bournout and didactics of mathematics. (email: ikram. douelfiqar@uit.ac.ma)

Youssef El Madhi is a Moroccan qualified professor specialized in education, environment, and public health. He is a Ph.D. Research Scholar in Biology and Health. He is the head of Research Laboratory for Education, Environment and Health, CRMEF Rabat, Morocco, Project leader with the "Agence Universitaire de la Fran-cophonie". The research project entitled: Study of Psychosocial Stressors Factors among trainee teachers at the CRMEF Rabat-Salé-Kenitra. Establish a Prevention Approach. His current research focuses on Education, biometry, epidemiology, public health, and burnout syndrome. (email: youssmad@yahoo.fr)

Hanan El Faylali is a professor of informatics, systems and optimization at Ibn Tofail University, her current research includes fifth generation wireless applications. (email: hanan.elfaylali@uit.ac.ma).

Article submitted 2021-11-02. Resubmitted 2021-12-20. Final acceptance 2021-12-21. Final version published as submitted by the authors. 